This item was submitted to Loughborough's Research Repository by the author.

Items in Figshare are protected by copyright, with all rights reserved, unless otherwise indicated.

\title{
Surface acceleration transmission during drop landings in humans
}

PLEASE CITE THE PUBLISHED VERSION

https://doi.org/10.1016/j.jbiomech.2021.110269

PUBLISHER

Elsevier BV

VERSION

AM (Accepted Manuscript)

PUBLISHER STATEMENT

This paper was accepted for publication in the journal Journal of Biomechanics and the definitive published version is available at https://doi.org/10.1016/j.jbiomech.2021.110269.

\section{LICENCE}

CC BY-NC-ND 4.0

\section{REPOSITORY RECORD}

McErlain-Naylor, Stuart, Mark King, and Sam Allen. 2021. "Surface Acceleration Transmission During Drop Landings in Humans". Loughborough University. https://hdl.handle.net/2134/13670032.v1. 


\title{
Surface acceleration transmission during drop landings in humans
}

\author{
S.A. McErlain-Naylor ${ }^{1,2}$, M.A. King ${ }^{1}$, and S.J. Allen ${ }^{1}$ \\ ${ }^{1}$ School of Sport, Exercise, and Health Sciences, Loughborough University, Loughborough, United Kingdom \\ ${ }^{2}$ School of Health and Sports Sciences, University of Suffolk, Ipswich, United Kingdom
}

\begin{abstract}
The purpose of this study was to quantify the magnitude and frequency content of surfacemeasured accelerations at each major human body segment from foot to head during impact landings. Twelve males performed two single leg drop landings from each of 0.15 $\mathrm{m}, 0.30 \mathrm{~m}$, and $0.45 \mathrm{~m}$. Triaxial accelerometers $(2000 \mathrm{~Hz})$ were positioned over the: first metatarsophalangeal joint; distal anteromedial tibia; superior to the medial femoral condyle; L5 vertebra; and C6 vertebra. Analysis of acceleration signal power spectral densities revealed two distinct components, $2-14 \mathrm{~Hz}$ and $14-58 \mathrm{~Hz}$, which were assumed to correspond to time domain signal joint rotations and elastic wave tissue deformation, respectively. Between each accelerometer position from the metatarsophalangeal joint to the L5 vertebra, signals exhibited decreased peak acceleration, increased time to peak acceleration, and decreased power spectral density integral of both the 2-14 Hz and 14-58 $\mathrm{Hz}$ components, with no further attenuation beyond the L5 vertebra. This resulted in peak accelerations close to vital organs of less than $10 \%$ of those at the foot. Following landings from greater heights, peak accelerations measured distally were greater, as was attenuation prior to the L5 position. Active and passive mechanisms within the lower limb therefore contribute to progressive attenuation of accelerations, preventing excessive accelerations from reaching the torso and head, even when distal accelerations are large. Keywords: accelerometer; bone stimulus; tibial acceleration; impact load; training load
\end{abstract}

\section{INTRODUCTION}

Impacts are inevitable in many human activities. During a drop landing, the feet experience ground reaction forces as great as ten times bodyweight (Edwards, Steele, $\&$ McGhee, 2009). These forces cause accelerations that are transferred through the tissues of the human musculoskeletal system from the foot to the head (Moran \& Marshall, 2006; Zhang, Derrick, Evans, \& Yu, 2008). Large impacts can result in the propagation of elastic waves through the soft tissue of the body (Furlong, Voukelatos, Kong, \& Pain, 2019). Compliance in the form of joint rotations and tissue deformation prolongs the impact and, alongside progressively greater segment masses, reduces accelerations in a distal-to-proximal manner, preventing excessive accelerations at the brain and other vital organs (Hamill, Derrick, \& Holt, 1995; Pozzo, Berthoz, Lefort, \& Vitte, 1991). Joint rotations reduce the effective axial stiffness of the body, a mechanism of limiting ground reaction forces and hence accelerations during impacts (Lafortune, Lake, \& Hennig, 1996; Zhang, Bates, \& Dufek, 2000). Further contributors to acceleration attenuation include medial longitudinal foot arch compliance (Hageman, Hall, Sterner, \& Mirka, 2011), heel pad deformation (Pain \& Challis, 2001), compliance within joint structures (Hoshino \& Wallace, 1987), spinal compression (Helliwell, Smeathers, \& Wright, 1989), and soft tissue movement (Furlong et al., 2019; Pain \& Challis, 2002).

Impact attenuation within lower limb joints has been investigated using cadavers; under the same applied impact load, the peak force transmitted through an isolated knee joint compared with an intact knee increased sequentially as lateral and medial menisci were cut $(+13 \%)$, menisci and soft tissue removed $(+21 \%)$, cartilage and sub- 
chondral bone removed ( $+35 \%)$, and with a total knee replacement $(+80 \%)$ (Hoshino \& Wallace, 1987). Shank and thigh soft tissue displacement of up to $1.4 \mathrm{~cm}$ relative to the underlying bone (Furlong et al., 2019) will also contribute to force and acceleration attenuation throughout the leg. Impacts simulated via a model comprising a heel pad linked to a rigid shank resulted in peak forces over $100 \%$ greater than a model with the heel pad attached to a shank with a wobbling mass (Pain \& Challis, 2001). In the upper body, flexion of the spine at upper cervical levels and extension at lower cervical levels has been observed in low speed rear-end car crash impacts (Deng, Begeman, Yang, Tashman, \& King, 2000) and it has been shown that the vertebrae of healthy controls, but not participants with spinal fusion, are able to attenuate shock at frequencies above $15 \mathrm{~Hz}$ (Helliwell et al., 1989).

The mechanical vibration literature offers additional insights into elastic wave transmission through the human body. Maximal acceleration integrals following platform-induced vibrations have been reported to be approximately 4.5 and 11 times greater at the lower legs when compared to the hips and head respectively (Sonza, Völkel, Zaro, Achaval, \& Hennig, 2015). Substantial amplification of peak acceleration can occur between $10 \mathrm{~Hz}$ and $40 \mathrm{~Hz}$ at the ankle, $10 \mathrm{~Hz}$ and $25 \mathrm{~Hz}$ at the knee, $10 \mathrm{~Hz}$ and $20 \mathrm{~Hz}$ at the hip, and at $10 \mathrm{~Hz}$ at the spine (Kiiski, Heinonen, Järvinen, Kannus, \& Sievänen, 2008). Beyond these frequencies, the transmitted vibration power declined to between a tenth and a thousandth of that delivered by the platform. The human body is therefore capable of attenuating higher frequency mechanical waves in a distal-toproximal manner. Transmissibility of vibrations is affected by body segment mass (Mansfield, 2005), body kinematics (Harazin \& Grzesik, 1998; Matsumoto \& Griffin, 1998; Paddan \& Griffin, 1993), and muscle activity (Wakeling, Nigg, \& Rozitis, 2002). The damping coefficients of soft tissue increase with muscle force (von Tscharner, 2000) and shortening velocity (Wakeling \& Nigg, 2001), leading to energy absorption by the muscle during vibrations due to detachment and cycling of cross bridges.

Existing knowledge of in vivo whole-body impact elastic wave reduction largely stems from surface-mounted accelerometer investigations. The majority of studies have attached accelerometers to the tibia and forehead of participants in activities including walking (Forner et al., 1995; Light, McLellan, \& Klenerman, 1980; LucasCuevas et al., 2013; Voloshin, Wosk, \& Brull, 1981), running (Derrick, Hamill, \& Caldwell, 1998; Hamill et al., 1995; Shorten \& Winslow, 1992), and landing (Zhang et al., 2008). These studies have consistently reported lower peak accelerations at the forehead compared with the tibia. A limited number of studies have shown the same pattern of distal-to-proximal acceleration reduction at additional positions such as the medial femoral condyle (Voloshin \& Wosk, 1983; Voloshin \& Wosk, 1982; Wosk \& Voloshin, 1981) or sacrum (Henriksen et al., 2008) but none has quantified the progressive reduction at each body segment from foot to head.

Such acceleration-time signals include relatively lower frequency components due to joint rotations, as well as relatively higher frequency components due to electrical noise or resonance in the accelerometer attachment. For example, Shorten and Winslow (1992) utilised power spectral analysis to identify two major components of the typical tibia acceleration power spectrum during treadmill running, corresponding to the active $(5-8 \mathrm{~Hz})$ and impact-related $(12-20 \mathrm{~Hz})$ phases of the time-domain ground reaction force. Both the amplitude and frequency of tibial accelerations increased with increasing running speed, with the greatest attenuation between tibia and head occurring in the range of $15-50 \mathrm{~Hz}$. Attenuation increased with increasing running speed, suggesting that shock attenuating mechanisms limit transmission of accelerations to the head despite increases in ground reaction force. Following even greater ground reaction forces in bilateral drop landings, Zhang et al. (2008) found that 
drop height had no significant effect on acceleration signal attenuation (average transfer function from 21 to $50 \mathrm{~Hz}$ ) between the tibia and forehead. A maximal capacity to attenuate accelerations may therefore be implied. These studies offer no quantification of acceleration attenuation below the tibia or at sites between the tibia and head.

The purpose of the present study was therefore to quantify the magnitude and frequency content of surface-measured accelerations at each major human body segment from foot to head during impact landings. It was hypothesised that: 1) peak acceleration, median frequency, and power spectral density integral content within the frequency ranges corresponding to both joint rotations and the elastic wave, would each decrease for acceleration signals at progressively more superior body segments; 2) greater landing heights would lead to increases in these measures at all positions below the neck; 3) peak accelerations would occur temporally later at more superior body segments. This will be the first study using such measures to quantify the progressive transfer of accelerations between multiple adjacent body segments (i.e. foot - shank - thigh - lower back - upper back) and the signal energy losses associated with both joint rotations and tissue compliance during in vivo impact landings.

\section{METHODS}

\section{Participants}

Twelve recreationally active males (minimum two sport sessions per week) participated in this study (age: $30 \pm 7$ years; height: $1.78 \pm 0.06 \mathrm{~m}$; mass: $77.4 \pm 7.0$ $\mathrm{kg}$ ). Each participant was free from any injuries, had refrained from strenuous physical activity for $36 \mathrm{~h}$, and completed a health screen questionnaire prior to taking part. Testing procedures were explained in accordance with Loughborough University ethical guidelines, and each participant completed an informed consent form. All procedures were conducted according to the Declaration of Helsinki for studies involving human participants.

\section{Data Collection}

Following a self-selected warm up, participants performed two successful barefoot single (dominant) leg drop landings from each of $0.15 \mathrm{~m}, 0.30 \mathrm{~m}$, and $0.45 \mathrm{~m}$ onto a force platform (AMTI Inc., Watertown, MA; $600 \times 400 \mathrm{~mm}, 2000 \mathrm{~Hz}$ ). With the aim of inducing increasing distal impact accelerations from increasing drop heights, participants were instructed to maximise joint stiffness upon landing whilst keeping upper arms by their side with elbows flexed to $\sim 90^{\circ}$. Drop landings were used to mimic high impact sporting activities during which athletes attempt to maximise leg stiffness and hence ground reaction forces and performance outcomes associated with rapidly changing the momentum of the body (e.g. jump take-offs, cutting manoeuvres) in a controlled manner. Trials were considered successful if the participant landed with the dominant foot wholly on the force platform, was judged to have stepped off the box horizontally, and showed no visible changes in body configuration after landing with increasing drop heights.

Triaxial accelerometers (Dytran Instruments Inc., Chatsworth, CA; 2000 Hz; 10 grams; range: $100 \mathrm{~g}$; sensitivity: $50 \mathrm{mV} \cdot \mathrm{g}^{-1}$ ) were positioned (Figure 1) over the: 1) first metatarsophalangeal joint; 2) distal anteromedial tibia; 3) superior to the medial femoral condyle; 4) L5 vertebra; and 5) C6 vertebra. Accelerometers were held in position by elastic tape tightened to the limit of participant comfort with the z-axis 
aligned with the segment's longitudinal axis (Valiant, McMahon, \& Frederick, 1987; Ziegert \& Lewis, 1979). Resultant accelerations were used for all analyses. Ground reaction force and acceleration data were collected and synchronised through Vicon (Nexus 2.6.1; OMG Plc, Oxford, UK).
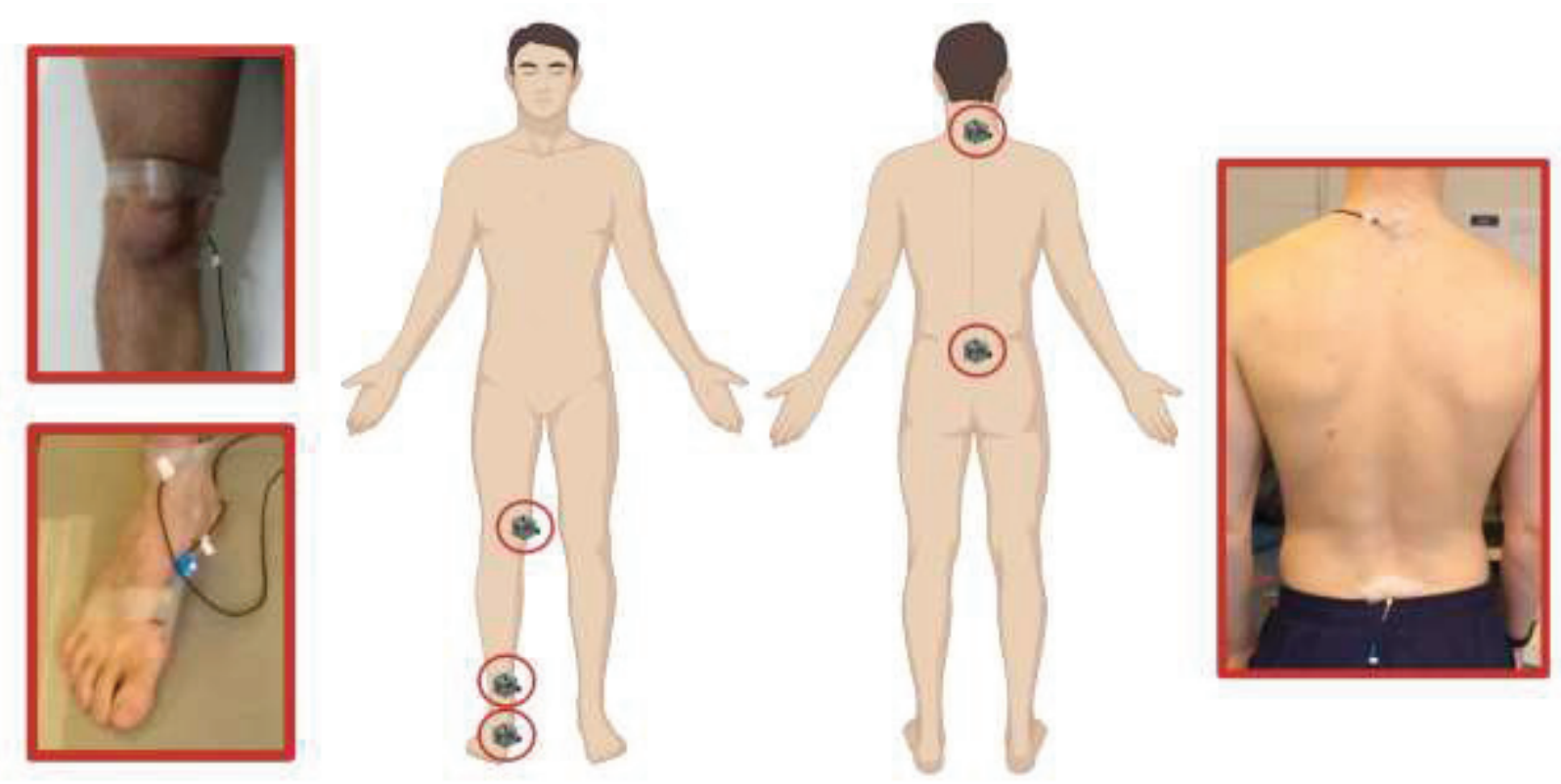

Figure 1 - Accelerometer positions and attachments. Created with BioRender.com

\section{Data Reduction}

All data reduction was performed in MATLAB (Version R2017b, The MathWorks Inc., Natick, MA). Time of first ground contact was identified for each trial as the first time point at which the vertical ground reaction force exceeded $10 \mathrm{~N}$. Beginning at first ground contact, a $0.1 \mathrm{~s}$ subsample of the time-domain resultant acceleration data was extracted, sufficient to capture the post-landing elastic wave (Shorten \& Winslow, 1992; Wakeling et al., 2002). Two time-domain parameters were identified for each accelerometer position: peak resultant acceleration; and its timing relative to first ground contact.

The power spectra of resultant accelerations were determined by Fast Fourier Transformation of the time-domain signals, using the same signal processing techniques for discontinuous and non-periodic signals as Shorten and Winslow (1992). The mean value of each signal was subtracted throughout the subsample and any linear trend was removed. To enable the analysis of frequency components in $2 \mathrm{~Hz}$ intervals (i.e. sampling frequency $\div$ number of data points), each subsample was padded with zeroes to a total sample duration of $0.5 \mathrm{~s}$ prior to Fast Fourier Transformation. This addition of $L$ zeroes to $N$ adjusted time-domain acceleration values reduces the calculated powers by a factor of $N /(N+L)$. The inverse of this factor was therefore applied to the calculated powers to obtain representative powers. The power spectral density of each signal frequency component was determined as the power of that component divided by the frequency interval $(2 \mathrm{~Hz})$. In accordance with Shorten and Winslow (1992), $2 \mathrm{~Hz}$ intervals were considered to provide sufficient resolution without the need for additional data padding.

As in previous literature (e.g. Shorten \& Winslow, 1992; Zhang et al., 2008), the power spectral densities of each acceleration signal at the most distal accelerometer position (first metatarsophalangeal joint) were visually inspected to identify common 
frequency ranges associated with the two main components: joint rotations; and the elastic wave. Three frequency-domain parameters were determined for each accelerometer position: median power spectral density frequency; and the power spectral density integral within the frequency ranges associated with each of the two components defined above. For each accelerometer position, parameter values were averaged for the two trials from each drop height.

\section{Statistical Analysis}

All statistical analyses were performed within JASP (Amsterdam, Netherlands) software Version 0.10. Data were presented as mean \pm standard deviation. A fully Bayesian inferential statistical approach (see Kruschke \& Liddell, 2018 for an introduction) was used to provide probabilistic statements for both the null and alternative hypotheses (Mengersen, Drovandi, Robert, Pyne, \& Gore, 2016; Sainani, 2018). Each analysis was conducted using the JASP default 'noninformative' prior (Wang, Chow, \& Chen, 2005). Bayesian two-way repeated measures ANOVA was used to evaluate the effects of accelerometer position (within) and drop height (between) on each parameter describing acceleration transmission. Bayes factor $\left(\mathrm{BF}_{10}\right)$ was reported to indicate the strength of the evidence for each analysis, interpreted as: $1 / 3<$ anecdotal $\leq 3 ; 3<$ moderate $\leq 10 ; 10<$ strong $\leq 30 ; 30<$ very strong $\leq 100$; extreme $>100$ (Lee \& Wagenmakers, 2013). Evidence for the alternative hypothesis $\left(\mathrm{H}_{1}\right)$ was set as $\mathrm{BF}_{10}>3$ and for the null hypothesis $\left(\mathrm{H}_{0}\right) \mathrm{BF}_{10}<1 / 3$. Frequentist $p$-values were also reported for the overall main and interaction effects for comparison but were not used to make inferences. Where a meaningful $\mathrm{BF}_{10}$ was discovered, a Bayesian post-hoc was performed (Westfall, Johnson, \& Utts, 1997). Markov Chain Monte Carlo with Gibbs sampling (10,000 samples) was used to make inferences, with 95\% credible intervals (Cl) (Harrison et al., 2020; Ly, Verhagen, \& Wagenmakers, 2016). Estimates of median standardised effect size (Cohen's $d$; ES) were calculated, and interpreted as: trivial < $0.2 ; 0.2 \leq$ small $<0.6 ; 0.6 \leq$ moderate < 1.2; $1.2 \leq$ large < 2.0; very large $\geq 2.0$ (Hopkins, Marshall, Batterham, \& Hanin, 2009).

\section{RESULTS}

The power spectra of first metatarsophalangeal joint acceleration signals contained two major distinct components (Figure 2): the first from $2 \pm 0 \mathrm{~Hz}$ to $14 \pm 1$ $\mathrm{Hz}$ on average; and the second from $15 \pm 1$ to $43 \pm 7 \mathrm{~Hz}$ on average, with a maximum upper limit of $58 \mathrm{~Hz}$. Signal content at frequencies greater than this second component were relatively negligible. As in previous studies, these components were considered to correspond to the low frequency joint rotations and higher frequency elastic wave tissue deformation related phases of the time-domain signals, respectively. The $2-14$ $\mathrm{Hz}$ and $14-58 \mathrm{~Hz}$ components were therefore identified as frequency ranges encompassing the joint rotations and elastic wave respectively for further analyses.

\section{Effects of accelerometer position}

Accelerometer position had a meaningful effect on all four dependent variables: magnitude of peak resultant accelerations (Figures $3 \& 4 ; \mathrm{BF}_{10}=\infty$, extreme; $p<$ 0.001 ); timing of peak resultant accelerations (Figures $3 \& 5$; $\mathrm{BF}_{10}=1.8 \times 10^{14}$, extreme; $p<0.001$ ); median power spectral density frequency (Figure 6; $\mathrm{BF}_{10}=12149$, extreme; $p=0.003$ ); and power spectral density integral within both the $2-14 \mathrm{~Hz}$ (Figure 7; $\mathrm{BF}_{10}=\infty$, extreme; $p<0.001$ ) and $14-58 \mathrm{~Hz}$ (Figure 7; $\mathrm{BF}_{10}=2.7 \times 10^{14}$, extreme; $p<0.001)$ ranges. 


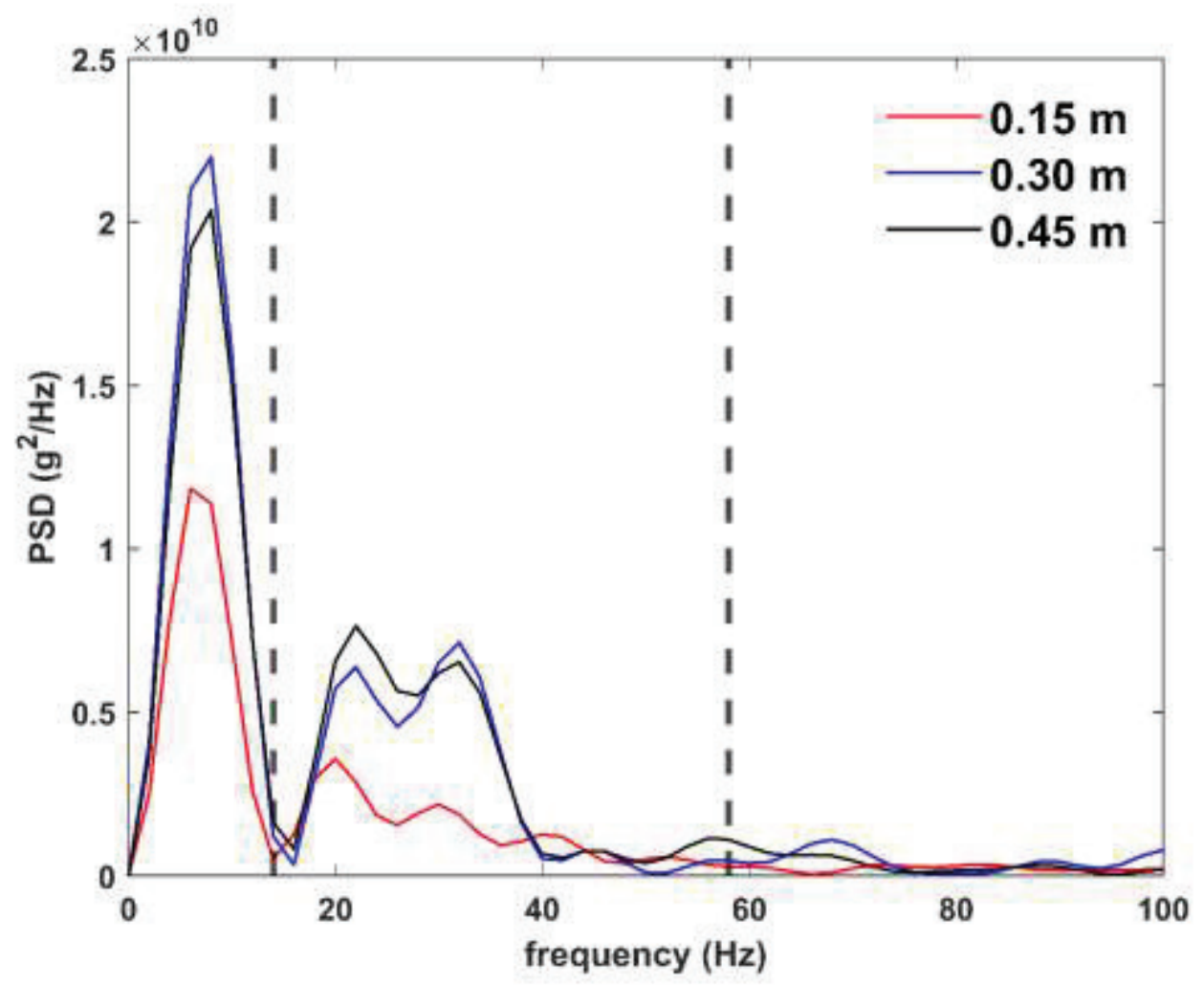

Figure 2 - Typical power spectral density plot for first metatarsophalangeal joint accelerometer signal (participant 3 ) for the first $100 \mathrm{~ms}$ following single-leg drop landings from each of $0.15,0.30$, and 0.45 $\mathrm{m}$. Dashed lines indicate $14-58 \mathrm{~Hz}$, identified as containing the second major frequency component for all trials, corresponding to the elastic wave.

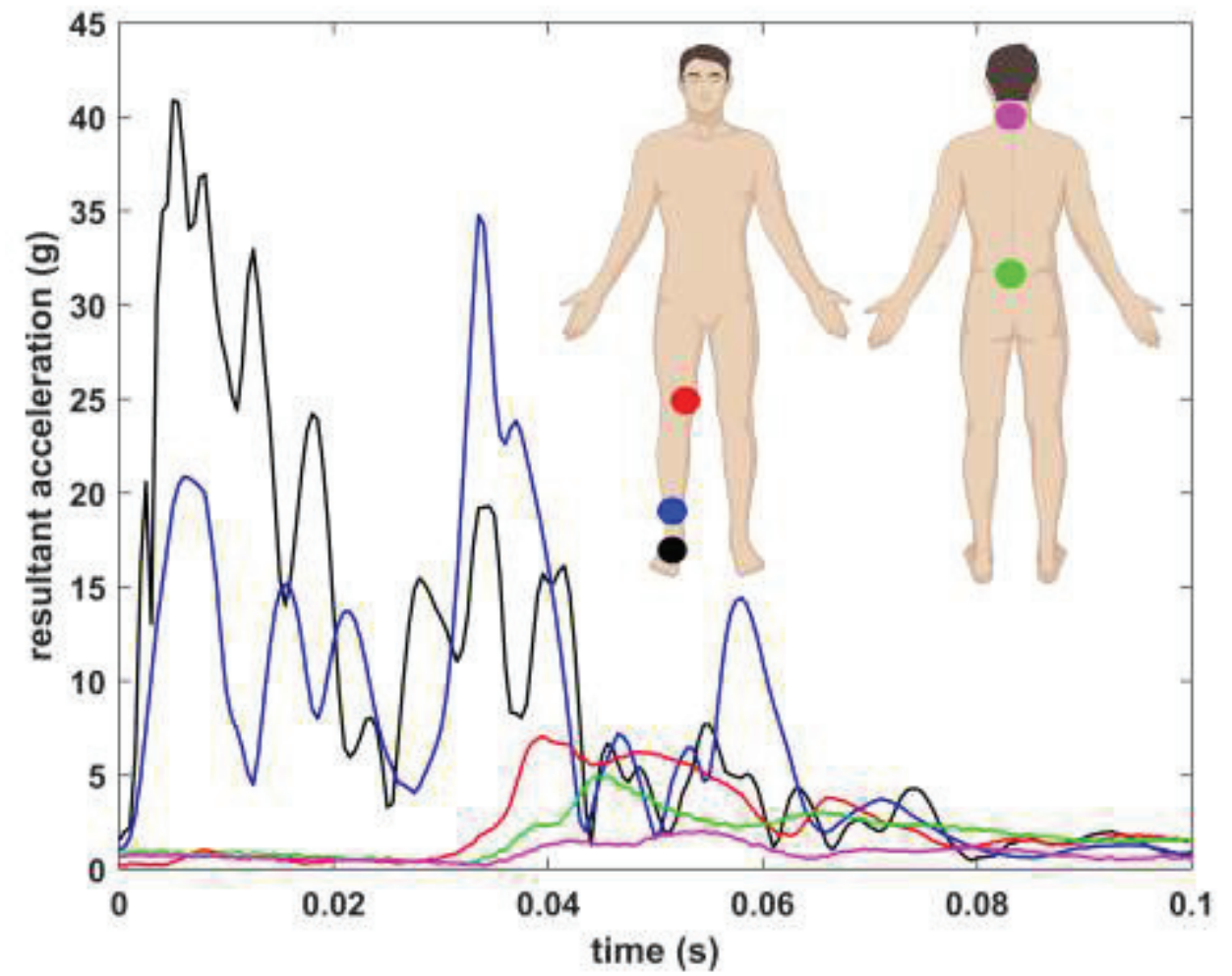

Figure 3 - Resultant acceleration at each accelerometer position for the first $100 \mathrm{~ms}$ of ground contact following a typical (participant 3 ) single-leg drop landing from $0.15 \mathrm{~m}$. Created with BioRender.com 


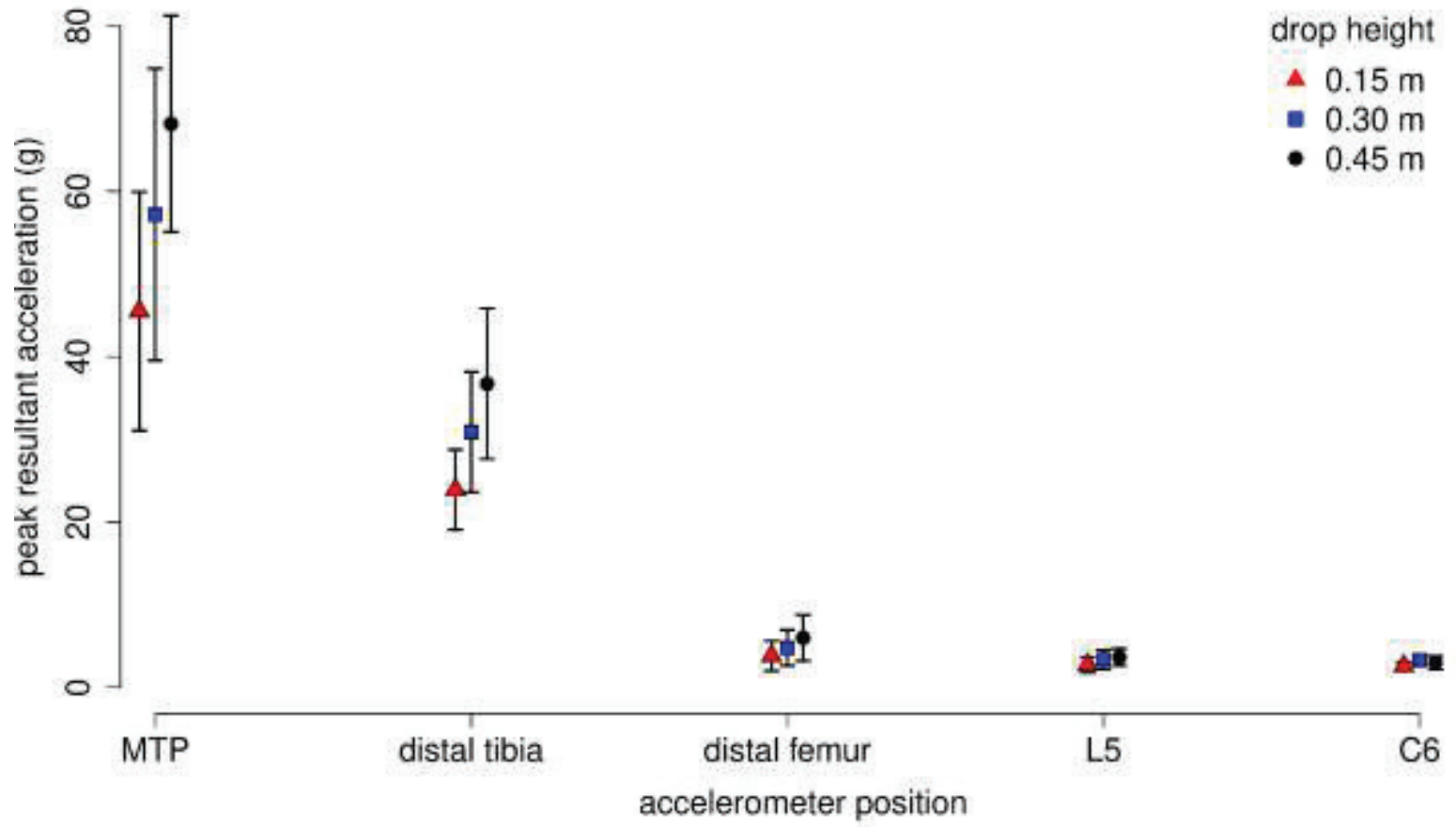

Figure 4 - Peak resultant acceleration at each accelerometer position following single leg drop landings from each of $0.15 \mathrm{~m}, 0.30 \mathrm{~m}$, and $0.45 \mathrm{~m}$. Bars show $95 \%$ credible intervals.

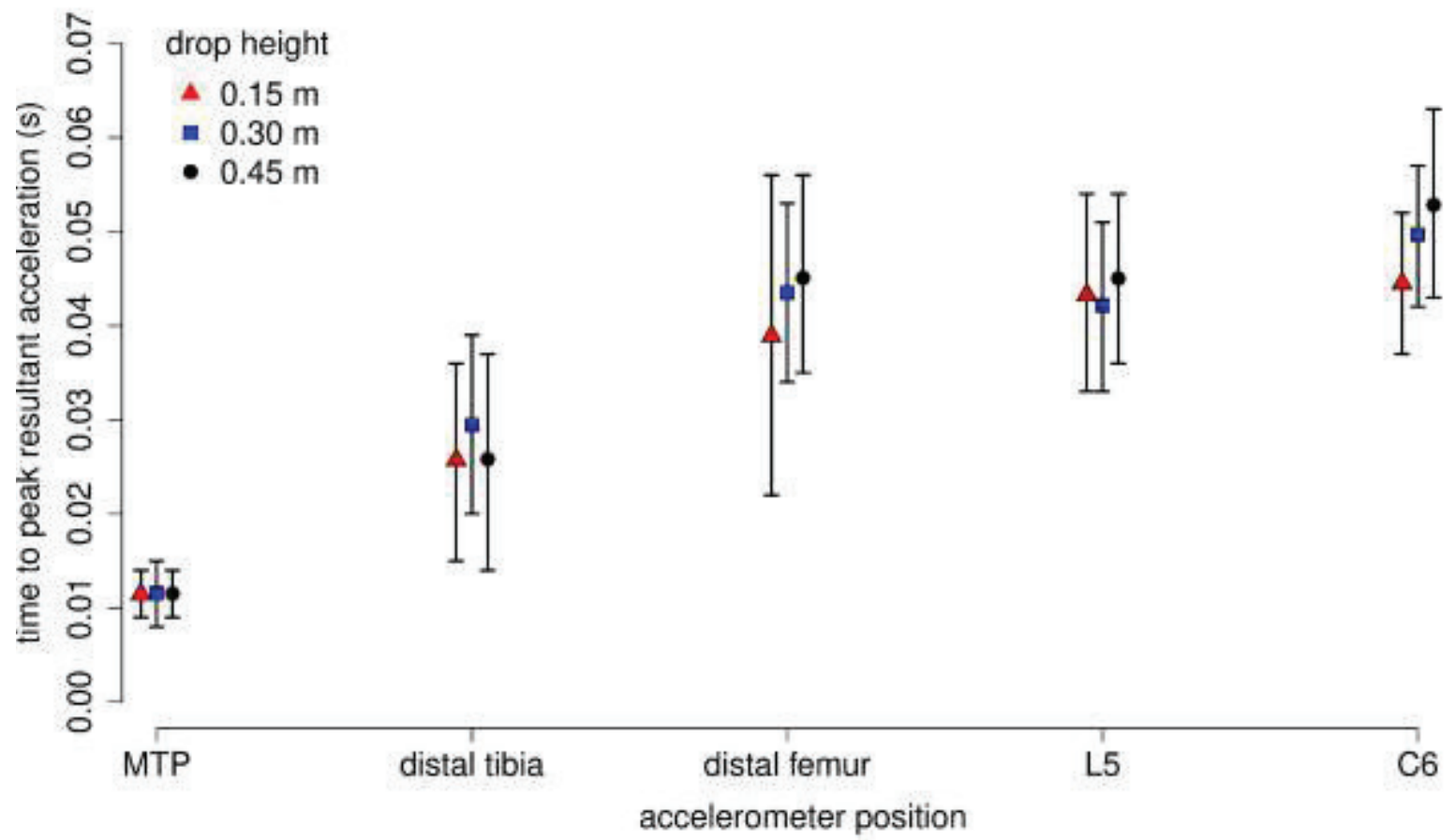

Figure 5 - Time of peak resultant acceleration relative to first ground contact at each accelerometer position following single leg drop landings from each of $0.15 \mathrm{~m}, 0.30 \mathrm{~m}$, and $0.45 \mathrm{~m}$. Bars show $95 \%$ credible intervals. 


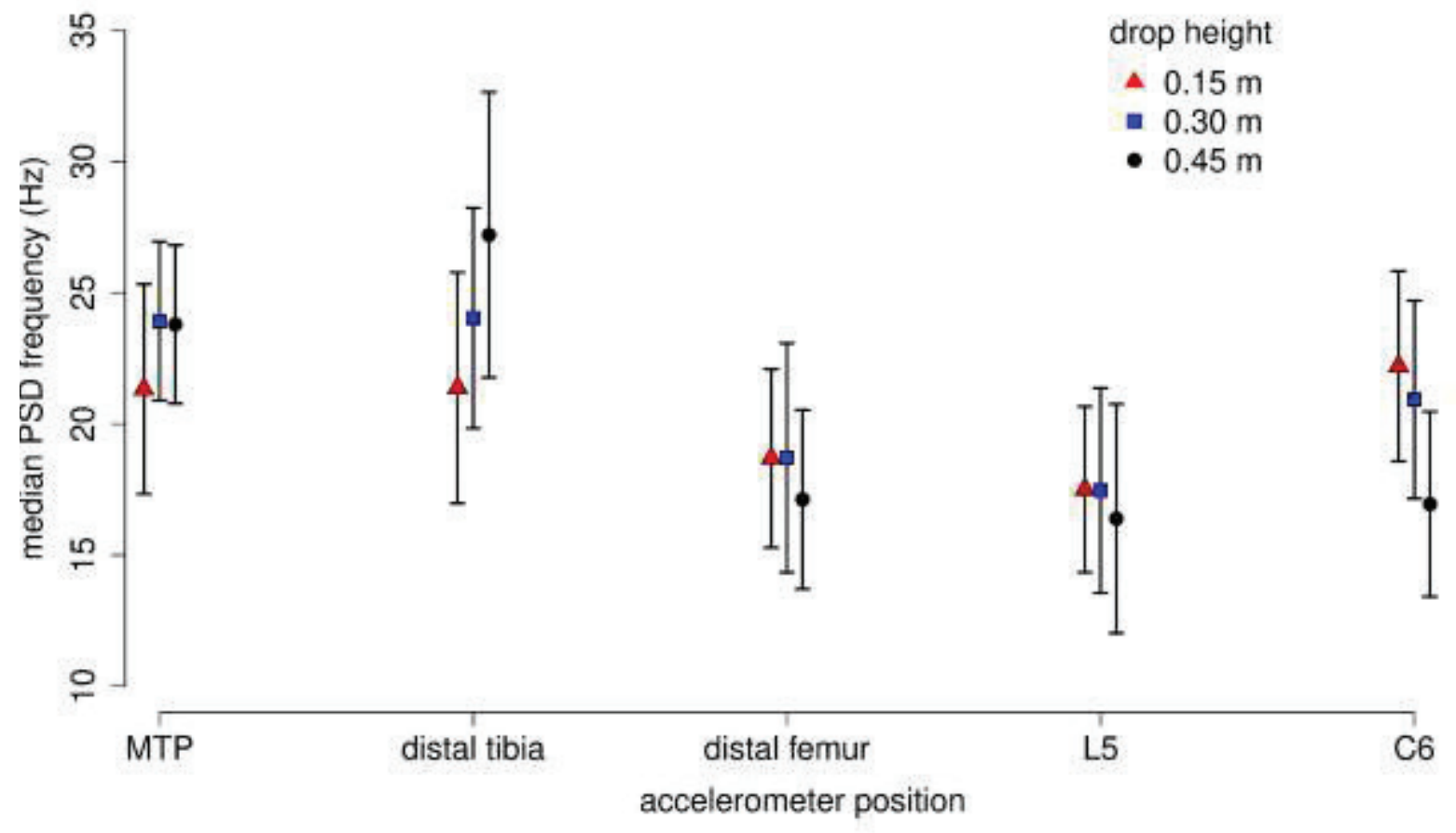

Figure 6 - Median power spectral density (PSD) frequency for the whole acceleration signal at each accelerometer position following single leg drop landings from each of $0.15 \mathrm{~m}, 0.30 \mathrm{~m}$, and $0.45 \mathrm{~m}$. Bars show $95 \%$ credible intervals.
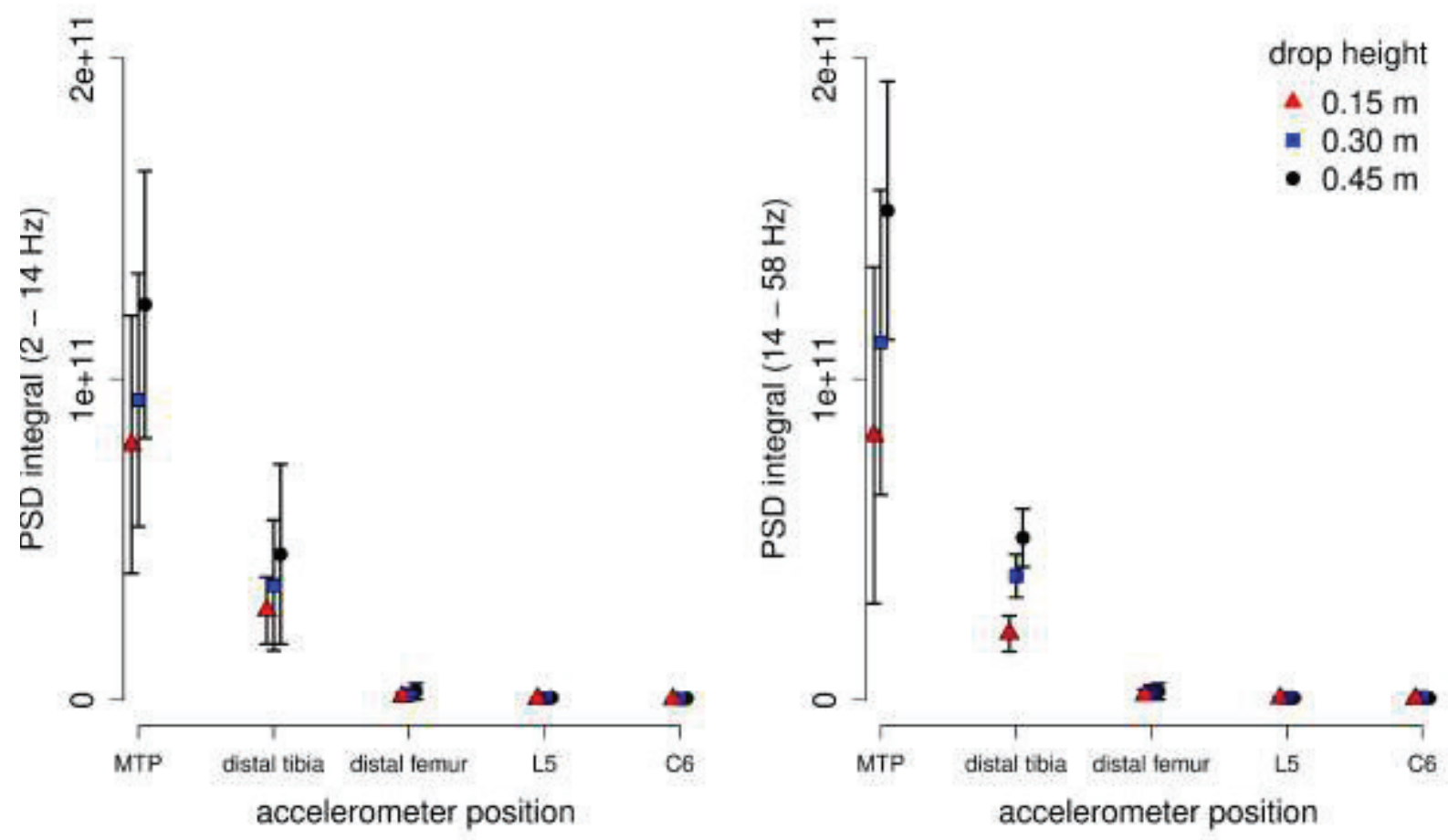

Figure 7 - Power spectral density (PSD) integrals associated with joint rotations (left: $2-14 \mathrm{~Hz}$ ) and the elastic wave (right: $14-58 \mathrm{~Hz}$ ) at each accelerometer position following single leg drop landings from each of $0.15 \mathrm{~m}, 0.30 \mathrm{~m}$, and $0.45 \mathrm{~m}$. Bars show $95 \%$ credible intervals. 
With every progressive step up the lower body (Table 1), peak resultant accelerations reduced and the acceleration signal power spectral density integrals relating to both frequency components $(2-14 \mathrm{~Hz}$ and $14-58 \mathrm{~Hz})$ were attenuated. There were no further differences in these parameters between L5 and C6. On average, compared with the metatarsophalangeal joint, peak resultant acceleration was reduced by $42 \pm 21 \%, 90 \pm 35 \%, 93 \pm 4 \%$, and $93 \pm 3 \%$ at the distal tibia, medial femoral condyle, L5, and C6 respectively (Figure 4).

Table 1. Bayesian post-hoc comparisons for adjacent accelerometer positions and drop heights.

\begin{tabular}{|c|c|c|c|c|c|c|c|c|c|c|}
\hline & \multicolumn{2}{|c|}{$\begin{array}{l}\text { peak resultant } \\
\text { acceleration }\end{array}$} & \multicolumn{2}{|c|}{$\begin{array}{l}\text { time of peak } \\
\text { resultant } \\
\text { acceleration }\end{array}$} & \multicolumn{2}{|c|}{$\begin{array}{c}\text { median PSD } \\
\text { frequency } \\
\text { (whole } \\
\text { signal) }\end{array}$} & \multicolumn{2}{|c|}{$\begin{array}{c}\text { PSD integral } \\
(2-14 \mathrm{~Hz})\end{array}$} & \multicolumn{2}{|c|}{$\begin{array}{c}\text { PSD integral (14 } \\
-58 \mathrm{~Hz})\end{array}$} \\
\hline & $\mathrm{BF}_{10}$ & ES & $\mathrm{BF}_{10}$ & ES & $\mathrm{BF}_{10}$ & ES & $\mathrm{BF}_{10}$ & ES & $\mathrm{BF}_{10}$ & ES \\
\hline \multicolumn{11}{|l|}{$\begin{array}{l}\text { accelerometer } \\
\text { position }\end{array}$} \\
\hline $\begin{array}{l}\text { MTP - } \\
\text { distal tibia }\end{array}$ & $5.5 \times 10^{5}$ & 1.35 & 9405 & 1.09 & 0.25 & 0.19 & $1.4 \times 10^{7}$ & 6.30 & 43253 & 1.21 \\
\hline $\begin{array}{l}\text { distal tibia - } \\
\text { distal femur }\end{array}$ & $8.5 \times 10^{12}$ & 2.74 & 1997 & 1.32 & 17.1 & 0.72 & 98226 & 4.30 & $4.8 \times 10^{11}$ & 4.46 \\
\hline $\begin{array}{l}\text { distal femur - } \\
\text { L5 }\end{array}$ & 7.10 & 0.52 & 0.19 & 0.09 & 0.22 & 0.13 & 4.19 & 1.71 & 5.75 & 0.49 \\
\hline $\begin{array}{l}\text { L5 - } \\
\text { C6 }\end{array}$ & 0.30 & 0.18 & 7.81 & 0.68 & 1.18 & 0.40 & 0.56 & 0.30 & 0.18 & 0.03 \\
\hline \multicolumn{11}{|l|}{ drop height } \\
\hline $\begin{array}{l}0.15 \mathrm{~m}- \\
0.30 \mathrm{~m}\end{array}$ & 10.6 & 0.98 & $N / A$ & $N / A$ & $N / A$ & $N / A$ & $N / A$ & $N / A$ & 5.07 & 0.85 \\
\hline $\begin{array}{l}0.30 \mathrm{~m}- \\
0.45 \mathrm{~m}\end{array}$ & 16.6 & 1.00 & $N / A$ & $N / A$ & $N / A$ & $N / A$ & $N / A$ & $N / A$ & 1.84 & 0.76 \\
\hline
\end{tabular}

PSD: power spectral density; $\mathrm{BF}_{10}$ : Bayes factor; ES: effect size; $N / A$ : post-hoc comparisons not performed because overall effect not meaningful in favour of the alternative hypothesis.

Peak accelerations were temporally delayed with every progressive step up the body, except between the medial femoral condyle and L5 (Table 1). The median signal frequency for the whole acceleration signal was lower at the medial femoral condyle and L5 than at the metatarsophalangeal joint and distal anteromedial tibia. There was no meaningful evidence of a difference in median frequency between other positions.

\section{Effects of drop height}

Drop height had a meaningful effect on the magnitude of peak resultant accelerations (Figure 4; $\mathrm{BF}_{10}=75.3$, very strong; $p<0.001$ ) and the $14-58 \mathrm{~Hz}$ power spectral density integral (Figure 7; $\mathrm{BF}_{10}=39.0$, very strong; $p<0.001$ ). Peak accelerations increased with each increase in drop height (Table 1). The power spectral density integral of the acceleration signal component relating to the elastic wave $(14-58 \mathrm{~Hz})$ was greater following drops from $0.30 \mathrm{~m}$ compared with $0.15 \mathrm{~m}$ but evidence of an increase between $0.30 \mathrm{~m}$ and $0.45 \mathrm{~m}$ was only anecdotal (Table 1). Drop height had no effect on timing of peak resultant accelerations (Figure 5; $\mathrm{BF}_{10}=$ 0.119 , moderate evidence for $\mathrm{H}_{0} ; p=0.512$ ) or median power spectral density frequency (Figure 6; $\mathrm{BF}_{10}=0.069$, strong evidence for $\mathrm{H}_{0} ; p=0.616$ ). The effect of drop height on the $2-14 \mathrm{~Hz}$ power spectral density integral was anecdotal, with no 
meaningful evidence in favour of the null or alternative hypothesis (Figure 7 ; $\mathrm{BF}_{10}=$ $0.654 ; p=0.017)$.

\section{Accelerometer position $x$ drop height interactions}

The effect of accelerometer position on peak resultant acceleration (Figure 4; $\mathrm{BF}_{10}=11.2$, strong; $\left.p<0.001\right)$ and elastic wave component integral (Figure $7 ; \mathrm{BF}_{10}=$ 24.6, strong; $p<0.001$ ) increased with increases in drop height (i.e. increased attenuation). There was no interaction effect on timing of peak resultant accelerations $\left(\mathrm{BF}_{10}=0.022\right.$, very strong evidence for $\mathrm{H}_{0} ; \mathrm{p}=0.683$ ) or median power spectral density frequency $\left(\mathrm{BF}_{10}=0.105\right.$, moderate evidence for $\left.\mathrm{H}_{0} ; \mathrm{p}=0.033\right)$. The interaction effect on the joint rotation component integral was anecdotal, with no meaningful evidence in favour of the null or alternative hypothesis (Figure 7; $\mathrm{BF}_{10}=0.447 ; p=0.003$ ).

\section{DISCUSSION}

This study quantified the characteristics of surface-measured accelerations throughout the body following an impact. Surface accelerations were attenuated in a distal-to-proximal manner between each accelerometer position from metatarsophalangeal joint to L5 vertebra but not beyond the L5 vertebra. This attenuation was generally characterised by a temporal delay as well as decreases in peak acceleration and median signal frequency. Peak accelerations and the attenuation prior to L5 were greater following landings from greater heights. The same attenuation pattern was observed in the energy (i.e. power spectral density integral) of both the lower frequency range $(2-14 \mathrm{~Hz})$ relating to joint rotations, and the higher frequency range $(14-58 \mathrm{~Hz})$ relating to the elastic wave. This is the first study using such measures to quantify the progressive transfer of accelerations between multiple adjacent body segments (i.e. foot - shank - thigh - lower back - upper back) and the signal energy losses associated with both joint rotations and tissue compliance during impact landings.

The progressive distal-to-proximal attenuation ensured that peak accelerations close to vital organs were less than $10 \%$ of those at the foot. Compliance in the lower limbs due to both joint rotations and tissue deformation acts to reduce the risk of serious injury to these organs by limiting accelerations transmitted from the impact. Not only did peak acceleration occur later at more superior sites, these superior sites were also less affected by the amplifying effect of greater drop heights. Whilst distal accelerations increased with each increase in drop height, compliance within the body associated with joint rotations and tissue deformation was capable of increasing attenuation of the accelerations between proximal sites. This ensured that greater impact forces and consequent distal accelerations did not lead to greater accelerations at the torso and head. It is not clear to what extent features within the trunk would contribute to attenuation of any excessive accelerations reaching the L5 vertebra as this did not occur in the present study. Indeed, the vertebrae of healthy controls, but not participants with spinal fusion, are able to attenuate shock at frequencies above $15 \mathrm{~Hz}$ (Helliwell et al., 1989), similar to the $14-58 \mathrm{~Hz}$ elastic wave component identified in the present study. Furthermore, it is not clear whether the lack of attenuation above $\mathrm{L} 5$ reflects the relative lack of joint rotation above this position. Previous studies have reported unchanged peak head acceleration (Hamill et al., 1995) and increased attenuation between tibia and head with increased running speeds (Shorten \& Winslow, 1992).

The present findings, together with those of Hamill et al. (1995) and Shorten and Winslow (1992), contrast with Zhang et al. (2008) who reported that drop height had no effect on impact attenuation between the tibia and the forehead during bilateral drop 
landings. However, the $21-50 \mathrm{~Hz}$ frequency component identified by Zhang et al. (2008) as representative of the elastic wave more closely resembles the present study's $14-58 \mathrm{~Hz}$ range than Shorten and Winslow's (1992) 12 - $20 \mathrm{~Hz}$ during treadmill running. A secondary analysis of the $21-58 \mathrm{~Hz}$ power spectral density integral in the present study reported similar results to the $14-58 \mathrm{~Hz}$ range (accelerometer position BF10 = $\infty$; drop height BF10 $=50.6$; interaction effect BF10 $=38.3)$. The differences in results therefore cannot be attributed to the difference in lower frequency band (14 Hz vs 21 $\mathrm{Hz}$ ) of the elastic wave component. Results were likewise unaffected when only the tibia and C6 accelerometers were analysed and so this difference cannot be attributed to the present study's inclusion of acceleration attenuations distal to the tibia or a greater number of measurement sites. Counterintuitively, it is possible that unilateral landings offer greater capacity than bilateral landings for increasing attenuation following drops from greater height. High frequency vibration transmission to the thoracic vertebrae has been shown to be lower in unilateral stance compared with bilateral stance, possibly due to coupled rotational motion of the whole upper body about the hip joint (Matsumoto \& Griffin, 1998).

Quantifying the relative contributions of specific structures (e.g. soft tissue motion or compliance within joint structures) to the reported attenuation is beyond the scope of this study. Future studies may wish to investigate these specific contributions, especially given potential implications for the modelling of high impact activities in whole-body inverse and forward dynamics investigations. Underestimating peak segment accelerations due to excessive filtering of marker trajectories results in overestimation of intersegmental forces and moments via inverse dynamics (Bobbert, Yeadon, \& Nigg, 1992). These errors propagate between segments in a distal-to-proximal manner (Tomescu, Bakker, Beach, \& Chandrashekar, 2018). Similarly, it may be speculated that failure to consider compliance within joint structures could lead to errors in segment accelerations and hence also in calculated kinetics. In forward-dynamics simulations of high-impact activities, excessive foot-ground spring compression has been necessary to match experimentally recorded ground reaction forces and performance outcomes due to a lack of compliance elsewhere in the rigid-body link system (Allen, King, \& Yeadon, 2012). This was despite the inclusion of wobbling masses representing soft tissue motion. The authors concluded that compliance must be incorporated elsewhere in the link system to accurately estimate internal forces during high-impact activities. It may be further speculated that the inclusion of participant-specific anatomical constraints during static optimisation (Glitsch \& Baumann, 1997; Leardini et al., 2017) and/or elastic components (e.g. Richard, Lamberto, Lu, Cappozzo, \& Dumas, 2016) when representing the connection between adjacent body segments may improve the accuracy of estimated internal kinetics where impacts are involved. This may also improve the timing of modelled elastic wave transmission (Allen et al., 2012), typically instantaneous in rigid systems but not in vivo as demonstrated by this study. Whilst no attempt was made to isolate the effects of individual mechanical structures, the present study offers some time- and frequency-domain insight into the separate contributions of joint rotations and tissue compliance to the overall attenuation between adjacent body segments which is necessary in any biofidelic inverse or forward dynamics whole-body model. Likewise, this highlights the importance of researchers and practitioners monitoring post-impact accelerations close to their particular site of interest (Barrett et al., 2016; Greig, Emmerson, \& McCreadie, 2019).

In conclusion, this is the first study using time- and frequency-domain measures to quantify the progressive transfer of accelerations between multiple adjacent body segments (i.e. foot - shank - thigh - lower back - upper back) during in vivo impact landings. Mechanisms associated with both joint rotations and tissue compliance within 
the lower limb contribute to progressive attenuation and delay of accelerations, preventing excessive accelerations from reaching the torso and head. Distal accelerations are greater following landings from greater heights, but the body remains capable of attenuating these accelerations before they reach the torso.

\section{REFERENCES}

Allen, S. J., King, M. A., \& Yeadon, M. R. (2012). Models incorporating pin joints are suitable for simulating performance but unsuitable for simulating internal loading. Journal of Biomechanics, 45(8), 1430-1436. https://doi.org/10.1016/j.jbiomech.2012.02.019

Barrett, S., Midgley, A. W., Towlson, C., Garrett, A., Portas, M., \& Lovell, R. (2016). Within-match PlayerLoad ${ }^{\mathrm{TM}}$ patterns during a simulated soccer match: potential implications for unit positioning and fatigue management. International Journal of Sports Physiology and Performance, 11(1), 135-140. https://doi.org/10.1123/ijspp.2014-0582

Bobbert, M. F., Yeadon, M. R., \& Nigg, B. M. (1992). Mechanical analysis of the landing phase in heel-toe running. Journal of Biomechanics, 25(3), 223-234. https://doi.org/10.1016/0021-9290(92)90022-S

Deng, B., Begeman, P. C., Yang, K. H., Tashman, S., \& King, A. I. (2000, November 1). Kinematics of human cadaver cervical spine during low speed rear-end impacts. https://doi.org/10.4271/2000-01-SC13

Derrick, T. R., Hamill, J., \& Caldwell, G. E. (1998). Energy absorption of impacts during running at various stride lengths. Medicine and Science in Sports and Exercise, 30(1), 128-135. https://doi.org/10.1097/00005768-199801000-00018

Edwards, S., Steele, J. R., \& McGhee, D. E. (2009). Does a drop landing represent a whole skill landing and is this moderated by fatigue? Scandinavian Journal of Medicine \& Science in Sports, 20(3), 516-523. https://doi.org/10.1111/j.16000838.2009.00964.x

Forner, A., García, A.-C., Alcántara, E., Ramiro, J., Hoyos, J.-V., \& Vera, P. (1995). Properties of shoe insert materials related to shock wave transmission during gait. Foot \& Ankle International, 16(12), 778-786. https://doi.org/10.1177/107110079501601207

Furlong, L.-A. M., Voukelatos, D., Kong, P. W., \& Pain, M. T. G. (2019). Changes in inertial parameters of the lower limb during the impact phase of dynamic tasks. Journal of Biomechanics, 109488. https://doi.org/10.1016/j.jbiomech.2019.109488

Glitsch, U., \& Baumann, W. (1997). The three-dimensional determination of internal loads in the lower extremity. Journal of Biomechanics, 30(11-12), 1123-1131. https://doi.org/10.1016/S0021-9290(97)00089-4

Greig, M., Emmerson, H., \& McCreadie, J. (2019). Quantifying functional ankle rehabilitation progression criteria using GPS: A preliminary study. Journal of Sport Rehabilitation, 28(7), 729-734. https://doi.org/10.1123/jsr.2018-0045

Hageman, E. R., Hall, M., Sterner, E. G., \& Mirka, G. A. (2011). Medial longitudinal arch deformation during walking and stair navigation while carrying loads. Foot \& Ankle International, 32(6), 623-629. https://doi.org/10.3113/FAl.2011.0623

Hamill, J., Derrick, T. R., \& Holt, K. G. (1995). Shock attenuation and stride frequency during running. Human Movement Science, 14(1), 45-60. https://doi.org/10.1016/0167-9457(95)00004-C 
Harazin, B., \& Grzesik, J. (1998). The transmission of vertical whole-body vibration to the body segments of standing subjects. Journal of Sound and Vibration, 215(4), 775-787. https://doi.org/10.1006/jsvi.1998.1675

Harrison, A. J., McErlain-Naylor, S. A., Bradshaw, E. J., Dai, B., Nunome, H., Hughes, G. T. G., ... Fong, D. T. P. (2020). Recommendations for statistical analysis involving null hypothesis significance testing. Sports Biomechanics, 19(5), 561-568. https://doi.org/10.1080/14763141.2020.1782555

Helliwell, P. S., Smeathers, J. E., \& Wright, V. (1989). Shock absorption by the spinal column in normals and in ankylosing spondylitis. Proceedings of the Institution of Mechanical Engineers, Part H: Journal of Engineering in Medicine, 203(4), 187190. https://doi.org/10.1243/PIME PROC 198920303701

Henriksen, M., Christensen, R., Alkjær, T., Lund, H., Simonsen, E. B., \& Bliddal, H. (2008). Influence of pain and gender on impact loading during walking: A randomised trial. Clinical Biomechanics, 23(2), 221-230. https://doi.org/10.1016/j.clinbiomech.2007.09.010

Hopkins, W. G., Marshall, S. W., Batterham, A. M., \& Hanin, J. (2009). Progressive statistics for studies in sports medicine and exercise science. Medicine and Science in Sports and Exercise, 41(1), 3-13. https://doi.org/10.1249/MSS.0b013e31818cb278

Hoshino, A., \& Wallace, W. A. (1987). Impact-absorbing properties of the human knee. The Journal of Bone and Joint Surgery. British Volume, 69(5), 807-811. Retrieved from http://www.ncbi.nlm.nih.gov/pubmed/3680348

Kiiski, J., Heinonen, A., Järvinen, T. L., Kannus, P., \& Sievänen, H. (2008). Transmission of vertical whole body vibration to the human body. Journal of Bone and Mineral Research, 23(8), 1318-1325. https://doi.org/10.1359/jbmr.080315

Kruschke, J. K., \& Liddell, T. M. (2018). Bayesian data analysis for newcomers. Psychonomic Bulletin \& Review, 25(1), 155-177. https://doi.org/10.3758/s13423017-1272-1

Lafortune, M. A., Lake, M. J., \& Hennig, E. M. (1996). Differential shock transmission response of the human body to impact severity and lower limb posture. Journal of Biomechanics, 29(12), 1531-1537. https://doi.org/10.1016/S0021-9290(96)80004$\underline{2}$

Leardini, A., Belvedere, C., Nardini, F., Sancisi, N., Conconi, M., \& Parenti-Castelli, V. (2017). Kinematic models of lower limb joints for musculo-skeletal modelling and optimization in gait analysis. Journal of Biomechanics, 62, 77-86. https://doi.org/10.1016/j.jbiomech.2017.04.029

Lee, M. D., \& Wagenmakers, E. J. (2013). Bayesian data analysis for cognitive science: A practical course. New York, NY: Cambridge University Press.

Light, L. H., McLellan, G. E., \& Klenerman, L. (1980). Skeletal transients on heel strike in normal walking with different footwear. Journal of Biomechanics, 13(6), 477-480. https://doi.org/10.1016/0021-9290(80)90340-1

Lucas-Cuevas, A. G., Pérez-Soriano, P., Bush, M., Crossman, A., Llana, S., CortellTormo, J. M., \& Pérez-Turpin, J. A. (2013). Effects of different backpack loads in acceleration transmission during recreational distance walking. Journal of Human Kinetics, 37(1), 81-89. https://doi.org/10.2478/hukin-2013-0028

Ly, A., Verhagen, J., \& Wagenmakers, E.-J. (2016). Harold Jeffreys's default Bayes factor hypothesis tests: Explanation, extension, and application in psychology. 
Journal of Mathematical Psychology, 72, 19-32. https://doi.org/10.1016/i.jmp.2015.06.004

Mansfield, N. J. (2005). Human response to vibration. Florida, US: CRC Press LLC.

Matsumoto, Y., \& Griffin, M. J. (1998). Dynamic response of the standing human body exposed to vertical vibration: influence of posture and vibration magnitude. Journal of Sound and Vibration, 212(1), 85-107. https://doi.org/10.1006/jsvi.1997.1376

Mengersen, K. L., Drovandi, C. C., Robert, C. P., Pyne, D. B., \& Gore, C. J. (2016). Bayesian estimation of small effects in exercise and sports science. PLOS ONE, 11(4), e0147311. https://doi.org/10.1371/journal.pone.0147311

Moran, K. A., \& Marshall, B. M. (2006). Effect of fatigue on tibial impact accelerations and knee kinematics in drop jumps. Medicine \& Science in Sports \& Exercise, 38(10), 1836-1842. https://doi.org/10.1249/01.mss.0000229567.09661.20

Paddan, G. S., \& Griffin, M. J. (1993). The transmission of translational floor vibration to the heads of standing subjects. Journal of Sound and Vibration, 160(3), 503-521. https://doi.org/10.1006/jsvi.1993.1041

Pain, M. T. G., \& Challis, J. H. (2001). The role of the heel pad and shank soft tissue during impacts: a further resolution of a paradox. Journal of Biomechanics, 34(3), 327-333. https://doi.org/10.1016/S0021-9290(00)00199-8

Pain, M. T. G., \& Challis, J. H. (2002). Soft tissue motion during impacts: Their potential contributions to energy dissipation. Journal of Applied Biomechanics, 18(3), 231242. https://doi.org/10.1123/jab.18.3.231

Pozzo, T., Berthoz, A., Lefort, L., \& Vitte, E. (1991). Head stabilization during various locomotor tasks in humans. II. Patients with bilateral peripheral vestibular deficits. Experimental Brain Research, 85(1), 208-217. https://doi.org/10.1007/bf00230002

Richard, V., Lamberto, G., Lu, T.-W., Cappozzo, A., \& Dumas, R. (2016). Knee kinematics estimation using multi-body optimisation embedding a knee joint stiffness matrix: a feasibility study. PLOS ONE, 11(6), e0157010. https://doi.org/10.1371/journal.pone.0157010

Sainani, K. L. (2018). The problem with "Magnitude-based Inference." Medicine \& Science in Sports \& Exercise, 50(10), 2166-2176. https://doi.org/10.1249/MSS.0000000000001645

Shorten, M. R., \& Winslow, D. S. (1992). Spectral analysis of impact shock during running. International Journal of Sport Biomechanics, 8(4), 288-304. https://doi.org/10.1123/ijsb.8.4.288

Sonza, A., Völkel, N., Zaro, M. A., Achaval, M., \& Hennig, E. M. (2015). A whole body vibration perception map and associated acceleration loads at the lower leg, hip and head. Medical Engineering \& Physics, 37(7), 642-649. https://doi.org/10.1016/j.medengphy.2015.04.003

Tomescu, S. S., Bakker, R., Beach, T. A. C., \& Chandrashekar, N. (2018). The effects of filter cutoff frequency on musculoskeletal simulations of high-impact movements. Journal of Applied Biomechanics, 34(4), 336-341. https://doi.org/10.1123/jab.20170145

Valiant, G. A., McMahon, T. A., \& Frederick, E. C. (1987). A new test to evaluate the cushioning properties of athletic shoes. In International Series on Biomechanics: Biomechanics $X-B$.

Voloshin, A. S., \& Wosk, J. (1983). Shock absorption of meniscectomized and painful knees: A comparative in vivo study. Journal of Biomedical Engineering, 5(2), 157161. https://doi.org/10.1016/0141-5425(83)90036-5 
Voloshin, A., \& Wosk, J. (1982). An in vivo study of low back pain and shock absorption in the human locomotor system. Journal of Biomechanics, 15(1), 21-27. https://doi.org/10.1016/0021-9290(82)90031-8

Voloshin, A., Wosk, J., \& Brull, M. (1981). Force wave transmission through the human locomotor system. Journal of Biomechanical Engineering, 103(1), 48-50. https://doi.org/10.1115/1.3138245

von Tscharner, V. (2000). Intensity analysis in time-frequency space of surface myoelectric signals by wavelets of specified resolution. Journal of Electromyography and Kinesiology, 10(6), 433-445. https://doi.org/10.1016/S1050-6411(00)00030-4

Wakeling, J. M., \& Nigg, B. M. (2001). Modification of soft tissue vibrations in the leg by muscular activity. Journal of Applied Physiology, 90(2), 412-420. https://doi.org/10.1152/jappl.2001.90.2.412

Wakeling, J. M., Nigg, B. M., \& Rozitis, A. I. (2002). Muscle activity damps the soft tissue resonance that occurs in response to pulsed and continuous vibrations. Journal of Applied Physiology, 93(3), 1093-1103. https://doi.org/10.1152/japplphysiol.00142.2002

Wang, H., Chow, S.-C., \& Chen, M. (2005). A Bayesian approach on sample size calculation for comparing means. Journal of Biopharmaceutical Statistics, 15(5), 799-807. https://doi.org/10.1081/BIP-200067789

Westfall, P., Johnson, W. O., \& Utts, J. M. (1997). A Bayesian perspective on the Bonferroni adjustment. Biometrika, 84(2), 419-427. https://doi.org/10.1093/biomet/84.2.419

Wosk, J., \& Voloshin, A. (1981). Wave attenuation in skeletons of young healthy persons. Journal of Biomechanics, 14(4), 261-267. https://doi.org/10.1016/00219290(81)90071-3

Zhang, S., Derrick, T. R., Evans, W., \& Yu, Y.-J. (2008). Shock and impact reduction in moderate and strenuous landing activities. Sports Biomechanics, 7(2), 296-309. https://doi.org/10.1080/14763140701841936

Zhang, S. N., Bates, B. T., \& Dufek, J. S. (2000). Contributions of lower extremity joints to energy dissipation during landings. Medicine and Science in Sports and Exercise, 32(4), 812-819. https://doi.org/10.1097/00005768-200004000-00014

Ziegert, J. C., \& Lewis, J. L. (1979). The effect of soft tissue on measurements of vibrational bone motion by skin-mounted accelerometers. Journal of Biomechanical Engineering, 101(3), 218-220. https://doi.org/10.1115/1.3426248 